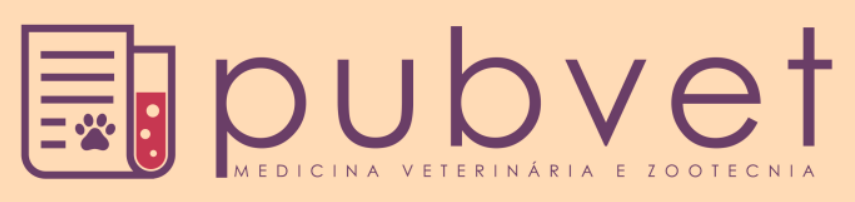

https://doi.org/10.22256/pubvet.v12n5a85.1-13

\title{
Fatores que alteram a produção e a qualidade do leite: Revisão
}

\author{
Matheus Hernandes Leira ${ }^{\bullet} 1^{*}$, Hortência Aparecida Botelho ${ }^{\ominus 2}$, Hadassa Cristhina \\ de Azevedo Soares dos Santos ${ }^{\bullet}$, Bianca Batista Barreto ${ }^{\ominus 3}$, Jorge Henrique Villela \\ Botelho ${ }^{\bullet}$, Gabriela Oliveira Pessoa 5
}

${ }^{1}$ Professor e Pesquisador, Doutor pela Universidade Federal de Lavras, Brasil

${ }^{2}$ Doutoranda em Zootecnia da Universidade Federal de Goiás, Brasil.

${ }^{3}$ Professora e Pesquisadora, Centro Universitário do Sul de Minas, UNIS.

${ }^{4}$ Doutorando em Medicina Veterinária da Universidade Jose do Rosário Vellano, Brasil.

${ }^{5}$ Doutoranda em Medicina Veterinária da Universidade Federal de Lavras, Brasil

*Autor para correspondência, E-mail. matheushernandes@uol.com.br

\begin{abstract}
RESUMO. Os principais fatores que afetam as características físico-químicas e microbiológicas do leite in natura estão relacionados aos cuidados zootécnicos e a obtenção e armazenagem adequadas do produto em propriedades rurais. Neste trabalho, abordam-se os principais aspectos que interferem na composição do leite, especialmente aqueles associados à alimentação das fêmeas em lactação. Os critérios de higiene e manejo dos animais durante a ordenha são enfocados, à luz da relação que apresentam, com a prevenção de mastites e a qualidade do leite. Destaca-se a importância do resfriamento do produto recém-ordenhado, bem como a necessidade de modernização do atual sistema de transporte do leite, desde o produtor até as usinas de beneficiamento, como instrumentos fundamentais para garantir a qualidade do leite de consumo e dos produtos lácteos.
\end{abstract}

Palavras chave: Produção leiteira, lactação, manejo

\section{Factors affecting milk production and quality: Review}

ABSTRACT. The main factors that affect the physical-chemical and microbiological characteristics of fresh milk are related to zootechnical care and the adequate production and storage of the product in rural properties. It article approach the main aspects that interfere in milk composition, especially those associated to the feeding of lactating females. The criteria of hygiene and management of the animals during the milking are focused, in the light of the relation that they present, with the prevention of mastites and the quality of the milk. The importance of the cooling of the freshly milked product is emphasized, as well as the need to modernize the current milk transportation system, from the producer to the processing plants, as fundamental instruments to guarantee the quality of the milk of consumption and the products dairy products.

Keywords: Dairy production, lactation, management

\section{Factores que alteran la producción y la calidad de la leche: Revisión}

RESUMEN. Los principales factores que afectan las características fisicoquímicas y microbiológicas de la leche in natura están relacionados con los cuidados zootécnicos y la obtención y almacenamiento adecuados del producto en propiedades rurales. Esta revisión trata sobre los principales aspectos que interfieren en la composición de la leche, especialmente aquellos asociados a la alimentación de las hembras en lactación. Los criterios de higiene y manejo de los animales durante el ordeño se enfocan, a la luz de la relación que presentan, con la prevención de mastitis y la calidad de la leche. Se destaca la 
importancia de la refrigeración del producto recién ordeñado, así como la necesidad de modernización del actual sistema de transporte de la leche, desde el productor hasta las plantas lácteas, como instrumentos fundamentales para garantizar la calidad de la leche de consumo y de los productos productos lácteos.

Palabras clave: Producción lechera, lactancia, manejo

\section{Introdução}

A pecuária leiteira é dividida em vários níveis organizacionais e tecnológicos, a começar de pequenas propriedades rurais até grandes cooperativas e laticínios (Willers et al., 2014). Esta prática é de extrema importância tanto no contexto social como no econômico, gerando empregos e obtenção de alimentos com qualidade (Werncke et al., 2016).

O leite é uma combinação de inúmeros elementos sólidos diluídos em água, constituído de lipídeos, carboidratos, proteínas, sais minerais e vitaminas (Prado et al., 2016). Esses elementos estão associados a vários fatores que alteram sua qualidade, como clima, manejo, condições higiênico-sanitárias, nutrição, temperatura de armazenagem e transporte do leite, bem-estar animal e presença de doenças no rebanho (Pereira et al., 2010). Com isso, é de grande relevância a realização de análises do leite para confirmação de sua qualidade, principalmente por um aumento das exigências das indústrias e consumidores. Os principais testes encontrados são: CCS (Contagem de células somáticas), CBT (Contagem Bacteriana Total), CIP (Contagem com Incubação Preliminar), CTLP (Contagem Total do Leite Pasteurizado), CC (Contagem de Coliformes) e CT (Cultura do Tanque para a Avaliação da Mastite) (Almeida et al., 2015). Outro fator amplamente discutido no que diz respeito na qualidade e produção do leite é o bemestar animal (Dawkins, 2017). Vacas leiteiras em todo o tipo de estresse tem sua performance produtiva e reprodutiva afetadas. Conforme o grau e período de intensidade do estresse, o desconforto gera níveis brandos, intermediários ou severos (Pereira et al., 2010).

Para realizar suas funções vitais, produtivas e reprodutivas, animais necessitam de nutrientes em qualidade e quantidade adaptável ao seu peso corporal, estado fisiológico, nível de produção, fatores ambientais e fatores externos (NRC, 2001). A alimentação é dos principais elementos que influenciam na qualidade do leite, necessitando de dietas com valores nutricionais balanceados.

\section{Colostro}

O colostro, tem constituição bastante diferente do leite já estabilizado (Romero et al., 2013). O colostro é um líquido viscoso e amarelado coletado do úbere logo após o nascimento do bezerro, com composição variável nas primeiras 72 horas (Sgarbieri, 2004). De acordo que as horas passam do pós-parto os nutrientes se alteram, aproximando-se a valores encontrados no leite, decrescendo suas quantidades nutricionais iniciais (Santos et al., 1995). Existe uma maior variação da proteína, de $16,4 \%$ para 6, 9\% com 60 horas pós-parto. Os teores de gordura, em torno de $6,1 \%$ não sofreram grandes alterações até 60 horas pósparto; porém existem variações, pois esses valores são influenciados pelo manejo, nutrição, individualidade, raça, número de parição, ração pré-parto, entre outros (Kehoe et al., 2007). O colostro é essencial para a defesa do neonato contra microrganismos como as bactérias e vírus, dado que as imunoglobulinas não estão presentes na corrente sanguínea do bezerro, em razão da constituição da placenta do bovino ser sindesmocorial, ou seja, o epitélio coriônico fica em contato direto com os tecidos uterinos, que impede a transferência de anticorpos da mãe para o feto durante a gestação (Tizard, 2002, Ocak \& Önder, 2011). Além de ser abundante em energia, vitaminas, minerais e proteínas, dos quais são indispensáveis para a saúde do bezerro, aumentando as chances de sobrevivência desse animal.

As altas taxas das proteínas de soro encontrada no colostro é de suma importância, pois as imunoglobulinas $\operatorname{IgG}, \operatorname{IgM}$ e $\operatorname{Ig} \mathrm{A}$ transferem imunidade passiva da mãe ao neonato; enquanto que as demais proteínas do soro, em geral, impulsionam o desenvolvimento e a maturação dos tecidos epiteliais do sistema gastrointestinal (Sgarbieri, 2004).

As principais proteínas do soro (imunoglobulina $\mathrm{G}$ ( $\mathrm{IgG})$, imunoglobulina A (IgA), $\propto$-lactalbumina $(\propto-\mathrm{La}), \beta$-lactoglobulina $(\beta$-Lg), albumina de soro bovino (BSA), lactoferrina (Lf) e lactoperoxidase (Lp)) diminuem no colostro em até 72 horas, que 
correspondem ao período de normalização do leite (Santos et al., 1994, Santos et al., 1988, Sgarbieri, 2004). Nos bovinos, a imunoglobulina mais predominante é a IgG, com cerca de $80 \%$ do conteúdo total (Grongnet et al., 1996).

\section{Fatores que influenciam na qualidade do leite}

A qualidade do leite cru pode ser influenciada por inúmeros fatores como, higiene da ordenha $\mathrm{e}$ dos utensílios, manejo, alimentação, genética dos rebanhos, obtenção, armazenagem e transporte do leite. Dentre esses, a infeção da glândula mamária, conhecida como mastite, compõem uma das principais causas que desempenham influência negativa sobre a qualidade e produção do leite (Costa et al., 2017). Além da mastite, existem outras doenças que acometem o rebanho leiteiro; porém com menos incidência, como a brucelose, tuberculose, salmonelose (também conhecida como paratifo dos bezerros), raiva, diarreia viral bovina (BVD), cisticercose bovina, manqueira entre outros (Duncan \& Prasse, 1982).

\section{Mastite}

A mastite é um processo inflamatório complexo da glândula mamária, principalmente acometida por bactérias, mas podendo ser também por outros tipos de microrganismos como os fungos, vírus e até mesmo por lesões físicas e estresse (Cerqueira et al., 2009, Costa et al., 1995). É considerada a doença de maior relevância no gado leiteiro, ocasionando prejuízos econômicos (Tozzetti et al., 2008). Esse prejuízo é devido a redução da produção de leite, despesas com remédios, auxilio veterinário, diminuição da qualidade, descarte do leite contaminado e descarte dos animais (Costa et al., 1995). É resultante da interação entre o animal, o microrganismo patogênico e o meio ambiente, sendo classificada em duas formas, a mastite clínica e a mastite subclínica (Oliveira et al., 2009). A mastite clínica é notada por respostas inflamatórias mais graves, com perceptíveis alterações na glândula mamária e no leite. Já a mastite subclínica é caracterizada por não apresentar alterações macroscópicas, sofrendo apenas alterações químicas e microbiológicas no leite (alta taxa de células imunológicas e células do epitélio descamado), o que dificulta a sua detecção e tratamento (Martins et al., 2010). Os relatos apontam que a mastite subclínica se difunde silenciosamente pelo rebanho sem que sejam notadas transformações macroscópicas do úbere ou de sua secreção (Barbalho \& Mota,
2005). Um correto controle e prevenção de mastites em uma propriedade deve alcançar níveis de ocorrência menores que $1 \%$ do rebanho leiteiro na sua forma clínica e menores que $15 \%$ para as manifestações subclínicas (Schvarz \& Santos, 2012).

Martins et al. (2010) em estudo sobre os microrganismos isolados dos casos de mastite clínica e subclínica em uma propriedade leiteira localizada na microrregião de Cuiabá- MT, apuraram a presença de mastite clínica em 5,8\% e subclínica $65,0 \%$ do rebanho. Com isso, observou-se o predomínio de mastites subclínicas em relação às mastites clínicas, 11,2 vezes maior. Uma vaca diagnosticada com mastite vai ter sua produção leiteira afetada em quantidade e qualidade, independente da forma ou da intensidade que se encontra, ocasionando até a perda de um ou mais tetos (Tozzetti et al., 2008).

Os microrganismos que frequentemente transmite a doença são separados em dois grandes grupos referentes a sua origem e o modo de transmissão. Os patógenos contagiosos são adequados a viver dentro da glândula mamária, disseminados principalmente durante a ordenha. Alguns exemplos incluem o Staphylococcus aureus, Streptococcus agalactiae e Staphylococcus sp. Já os patógenos ambientais, são invasores oportunistas, que não são adaptados a subsistir no seu interior, estão presentes no ar, na cama, na água e nas fezes, como a Escherichia coli, Streptococcus uberis, Pseudomonas $s p$, fungos, principalmente leveduras e algas aclorofiladas, do gênero Prototheca sp. (Costa et al., 1999, Mendonça et al., 1999). Esses patógenos contagiosos tem a habilidade colonizar o epitélio dos tetos, especialmente se a pele se encontra lesionada ou ressecada e conseguem elevar a contagem de células somáticas (CCS) ocasionando, em boa parte, a mastite subclínica de longa duração (Costa et al., 2017).

Há alguns testes para detecção da mastite bovina como a contagem de células somáticas (CCS), exame físico do úbere, aparência do leite em uma caneca de fundo escuro, Califórnia Mastitis Test (CMT), cultura e antibiograma (Costa et al., 2017).

Quando o leite proveniente da ordenha de toda a fazenda é misturado em um tanque, esse teste se mostra eficiente para indicar o predomínio da doença no rebanho. Normalmente a contagem gira em torno de 100.000 cels $/ \mathrm{ml}$, já com a mastite, os índices são maiores que 400.000 cels $/ \mathrm{ml}$. Em 
vacas individuais é feito o exame físico do úbere, observando se os quartos estão inchados, quentes e sensíveis ao toque, além da presença ou tamanho do tecido cicatricial quando o úbere estiver vazio. Em relação a aparência do leite, os primeiros jatos já permitem identificar se o leite está normal ou não, pela presença de coágulos, grumos ou coloração (aguado), devendo ser descartado se apresentar alguma dessas alterações (Tozzetti et al., 2008).

Neste contexto é importante estabelecer um programa para o controle de mastites na propriedade, onde o veterinário envolvido tem um papel significativo com o controle e a profilaxia da doença, além de comprometimento do proprietário e a participação efetiva principalmente do pessoal da ordenha para que haja êxito no processo (Langoni et al., 2015). A prevenção e controle da mastite engloba basicamente alguns pontos importantes como, o manejo adequado na ordenha, instalação apropriada, higienização dos equipamentos e do úbere do animal; manejo do animal seco; boa nutrição, descarte de vacas com infecção crônica, tratamento adequado, monitoração do estado de saúde do úbere, ambiente livre de estresse, educação sanitária para os ordenhadores, entre outros (Tozzetti et al., 2008).

\section{Higienização dos equipamentos de ordenha}

O equipamento limpo, higienizado é tão importante quanto a higiene na ordenha, sendo essencial para a qualidade do leite. Os principais passos da limpeza do equipamento consistem em enxágue com água morna em torno de $32^{\circ} \mathrm{C} \mathrm{a} 41^{\circ}$ $\mathrm{C}$, enxágue com água e detergente alcalino clorado de $71^{\circ} \mathrm{C}$ a $74^{\circ} \mathrm{C}$, enxágue ácido e santificação préordenha. Em relação a instalação e manutenção do equipamento, tem-se a necessidade de ser seguidas as regras internacionais (ISO 5707-3 A), dando destaque ao dimensionamento da bomba de vácuo, pulsação, troca de teteiras e nível de vácuo (Müller et al., 2002). As pessoas encarregadas de retirar, manipular, armazenar, transportar o leite, são muitas vezes causadores de contaminações, mas isso pode ser prevenido através de higiene pessoal e manipulação adequada (Schvarz \& Santos, 2012).

\section{Manejo e higiene na ordenha}

De acordo com Müller et al. (2002), a fase mais importante da atividade leiteira é a ordenha. Por consistir em controle da mastite e possibilitar a qualidade do leite. Ela deve ser executada por pessoas que possuem tranquilidade e que são treinadas, respeitando uma rotina préestabelecida. As seguintes etapas são fundamentais para uma ordenha correta:

Teste da caneca: Este teste permite o diagnóstico da mastite clínica e diminui o índice de contaminação do leite, consiste no exame dos primeiros jatos de leite, usando uma caneca de fundo escuro ou caneca telada;

Limpeza dos tetos com água clorada: Este procedimento visa a lavagem somente dos tetos e não do úbere. É obrigatoriamente necessário a utilização nas vacas com tetos visivelmente sujos (barro, fezes ou outra substância). Nos animais com tetos limpos pode ser otimizada;

Imersão dos tetos em solução antisséptica por 30 segundos: Conhecido como "pré-dipping", consiste na imersão dos tetos para desinfetá-los, durante 20 a 30 segundos de acordo com as instruções do fabricante;

Secagem dos tetos: Os tetos devem ser secos com papel toalha descartável, a fim de evitar que resíduos do desinfetante infecte o leite. Esta etapa é de extrema importância na higienização dos tetos já que associada à lavagem pode reduzir em 50 a $85 \%$ os índices de novas infecções. Quando da utilização do "pré- dipping" e não da lavagem dos tetos, os mesmos também devem ser secos com papel toalha visando à retirada do antisséptico. Este conjunto de procedimentos, além de propiciar a higienização dos tetos é de fundamental importância para uma ordenha mais rápida e completa. Associado a outros estímulos eleva os níveis de ocitocina que propicie a "descida" mais rápida do leite e intumescimento dos tetos, o que por sua vez permite a colocação correta dos insufladores, diminuindo os riscos de deslizamento das mesmas. O pré-estímulo deve durar de 40 segundos a 1 minuto.

Retirada dos insufladores: Para a retirada das teteiras deve ser fechado o registro de vácuo. A sobre ordenha deve ser evitada por provocar lesões nos tetos, que por sua vez predispõem a mastite. Quanto à retirada do leite residual, as opiniões dos pesquisadores divergem. Uma ligeira pressão sobre o conjunto de insufladores por alguns segundos propicia uma esgota mais completa.

Imersão dos tetos em solução antisséptica: A imersão dos tetos deve ocorrer imediatamente após a retirada dos insufladores, que deve ser total, utilizando-se frascos de imersão, não permitindo o 
retorno do produto. Este procedimento, associado ao tratamento de vacas secas, é responsável por uma diminuição significativa nas mastites contagiosas.

Desinfecção dos insufladores: A desinfecção das teteiras entre a ordenha de uma vaca e outra deve ser realizada pela imersão das mesmas em solução sanificante, que deve ser trocada com frequência. As quatro teteiras não devem ser imersas ao mesmo tempo. Nos equipamentos modernos, esta etapa de higienização é automatizada;

Ordem de ordenha: Estabelecer uma ordem de ordenha deixando as vacas infectadas para o final ou mesmo segrega-las.

\section{Qualidade da água}

A produção leiteira, de modo geral, considera a qualidade e quantidade da água essencial para suprir as necessidades dos seres vivos. Também é utilizada para limpeza dos equipamentos e na desinfecção das instalações em propriedades rurais, que garante a saúde humana e animal. Dessa forma, é necessária que todo o processo de síntese, armazenamento e transporte do leite seja feita com equipamentos devidamente limpos, utilizando água de qualidade (Cerqueira et al., 2009).

Infelizmente, é um dos fatores que os proprietários rurais não levam em conta ao desenvolver a atividade leiteira, contribuindo para ocorrência de perdas econômicas significativas, por grandes níveis de contaminação microbiana, aumento das taxas de mastite no rebanho, transmitindo doenças ao homem e aos animais (Cerqueira et al., 2009). A água para consumo e empregada no ambiente de ordenha, pode atuar como via de transmissão desses microrganismos, comprometendo a qualidade do leite, quando este entra em contato direto com os animais, ou a incorporação de parte da água residual vinda dos equipamentos (Lacerda et al., 2009).

Nas propriedades rurais é habitual a aplicação de água de inúmeras fontes e sem tratamento adequado, devido a oferta das águas de córregos, açudes, ribeirões, poços e/ou minas, serem mais fáceis de serem utilizadas; porém são mais passíveis a contaminações de microrganismos patogênicos e deteriorantes (Lacerda et al., 2009).

Nas indústrias também é essencial a utilização de uma água potável, especialmente, nas operações de processamento, higiene dos funcionários, higienização dos utensílios e máquinas, preparo de formulações, cozimento, torres de refrigeração, entre outros (Kamiyama \& Otenio, 2013).

Dentre os microrganismos patogênicos que podem ser transportados pela água, existem as bactérias do grupo coliformes, os microrganismos psicrotróficos como Pseudomonas spp., patógenos como Listeria monocytogenes, Salmonella spp., espécies de Staphylococcus produtoras de alguns tipos de toxinas. Com isso, pode haver um aumento da contagem total de bactérias (CTB) e a contaminação do leite e seus derivados por microrganismos de suma importância para a saúde pública (Lacerda et al., 2009).

\section{Aspectos físico-químico da água}

$\mathrm{O} \mathrm{pH}$ e a dureza constituem as principais características físico-químicas da água que são relevantes na limpeza e na desinfecção dos equipamentos e utensílios de ordenha. O nível de dureza é calculado a partir das somas das concentrações dos íons de cálcio e magnésio. Estes sais em taxas elevadas quando entram em contato com detergente alcalino, formam "pedras no leite" ou biofilme. Constitui precipitados insolúveis, que são crostas de cor branca, onde abrigam os microrganismos (Lagger et al., 2000, Ruzante \& Fonseca, 2001). Estes biofilmes produzem toxinas e enzimas que são agregados ao leite, e não são eliminados pelos processos térmicos de tratamento que contribui para a diminuição do tempo de conserva desses produtos (Lacerda et al., 2009).

No pré-enxague, há um aumento da temperatura, que precipita algumas proteínas favorecendo sua formação. São de difícil remoção, tornando-se fundamental o uso de detergentes ácidos em maiores concentrações e frequências que interfere nas propriedades do leite, que eleva os custos de produção, diminui a vida útil de alguns equipamentos, e reduz da eficiência da limpeza. Outras substâncias como, ferro, zinco, alumínio e manganês podem colaborar para a dureza da água. Deste modo a água utilizada deve ser de baixa dureza, para impedir a formação desses precipitados, conservando os equipamentos e reduzindo os custos de produção (Cerqueira et al., 2009).

$\mathrm{O} \mathrm{pH}$, é influenciado por condições ambientais como poluição e presença de rochas no solo pelo qual é incorporado seus sais. É um dos testes mais empregados na avaliação da qualidade da água, 
pois a utilização de água ácida pode corroer os equipamentos e neutralizar os detergentes alcalinos. Já as águas alcalinas podem neutralizar detergentes ácidos e aumentar a formação de precipitados, ambos exigindo um uso maior das quantidades de detergentes (Ruzante \& Fonseca, 2001). Outro aspecto importante é a presença de matéria orgânica de origem vegetal ou animal encontrada na água. Em grandes quantidades e temperaturas elevadas, irá acarretar uma diminuição intensa do oxigênio dissolvido, pela sua decomposição. Há um padrão máximo de material orgânico para a água ser considerável potável, que é 2mg/l (Cerqueira et al., 2009).

O cloro é extremamente eficaz para a destruição ou inativação de organismos patogênicos, sendo de simples aplicação, baixo custo, e relativamente seguro em doses recomendadas. A eficácia depende do tempo de ação do produto, que é no mínimo de 30 minutos, da taxa de cloro residual livre e do $\mathrm{pH}$ da água, que deve estar na faixa de 6,0 a 9,5 (Cerqueira et al., 2009). No entanto, o cloro possui uma deficiência na inativação de cistos e oocistos de protozoários e ovos de helmintos. Com isso, a filtração assume papel essencial na remoção desses organismos patogênicos (Kamiyama \& Otenio, 2013).

\section{Quantidade de água necessária}

A quantidade de água que é consumida pelas vacas, é influenciada por condições climáticas, tipo de alimento ingerido, característica da água e o estado de saúde do animal. Geralmente, uma vaca bebe de 40 a 60 litros de água por dia e dependendo da temperatura e da produção de leite esta quantia pode duplicar. Calcula-se 100 litros de água por vaca por dia, isto já incluindo a água utilizada para limpeza (Pereira et al., 2010).

\section{Bem-estar animal}

Os animais se estressam tanto quanto o ser humano, por exemplo, e isso gera uma perda na produção em até $30 \%$ ou mais de leite, dependendo de qual situação em que está gerando o estresse, e isso no rebanho é catastrófico em termos econômicos. $\mathrm{O}$ estresse traz consequências diretas para a saúde do animal, ele perde o apetite e sua imunidade fica baixa, tornando-o mais vulnerável às doenças. Os fatores que afetam o bem-estar animal incluem as instalações inadequadas, sujas, mal ventiladas e processo de irregularidade do piso. São problemas que incidem diretamente, causando dor, desconforto e estresse nos animais (Rodrigues et al., 2010). O conjunto existente entre animal e as interações ambientais, ainda não está totalmente definida, em virtude de se respeitar as particularidades pertencentes a cada espécie, adentro de cada uma delas, o indivíduo, a raça, o sexo e a sua idade, tendo que ainda, considerar as diferenças ambientais em que estes indivíduos permanecem, pois na produção animal um dos motivos que mais interfere é o clima, por prejudicar o bem-estar animal, principalmente no que se refere ao clima tropical, devido a sua maior tribulação ambiental (McDowell \& Jones, 1974).

O responsável essencial do desenvolvimento do calor corporal interno nos animais expostos é a radiação solar, que durante o dia, quase todo o calor consumido decorre disso, direta ou indiretamente, considerado um dos principais responsáveis do estresse nos animais. Desta forma, estruturas para sombreamento pretendem amenizar o efeito da radiação (Baêta \& Souza, $\underline{2010)}$.

\section{Sombreamento e sistemas de resfriamentos sobre a produção de vacas leiteiras}

O ambiente térmico desempenha forte atuação sobre a atividade animal, por prejudicar mecanismos de mudanças de calor e, assim, a regulação da oscilação térmica entre o animal e o meio. $\mathrm{O}$ animal dentro de um ambiente térmico apontado como adequado, produzirá de acordo com sua capacidade energética, em que as demarcações do ambiente especificadas como confortantes ou estressantes, podem ter alterações em função da região e dos tipos raças animais manuseados na propriedade (Perissinotto et al., 2007). Vacas leiteiras de elevada produção são mais receptivas aos efeitos do estresse térmico do que aquela de baixa produção láctea, já que situações ambientais estressantes, as vacas de alta produção possuem seu custo alimentar reduzido, e assim, os animais não obtém suas carências nutricionais atendidas, resultando em queda na produção de leite (Silva, 2000, Pereira, 2005).

Devido ao clima temperado os animais precisam de sombra nos horários mais quentes do dia, pode-se dizer, que em regiões de maior força de irradiação solar, como as de clima semiárido, por exemplo, instituir sombras que proporcionem maior conforto térmico pode ser mais eficaz, tendo em vista, as circunstâncias ambientais a que estão sujeitos por um extenso tempo do dia, o que se reproduz por vários meses do ano (Rodrigues et al., 2010). Por esse motivo a exigência da 
disponibilidade de sombras aos animais estabelecidos em locais de clima quente e seco, contribui na redução do seu estresse térmico, tendo que, é preciso fornecer o tipo de sombra que corresponda com necessidade de redução da irradiação solar disponível na região (Rodrigues et al., 2010).

\section{Compost badded parck barn}

O sistema Compost Badded Parck Barn é um dos métodos de confinamento que visa a melhorar o conforto e o bem-estar dos animais, diminuindo o estresse térmico e melhorando também a produtividade do rebanho. Nesse sistema, as vacas são confinadas em galpão com cama, em geral de serragem, que sofre decomposição microbiológica à medida que é adicionado o substrato orgânico (dejetos dos animais). O composto pode promover ganhos em bem-estar animal, que melhora de índices reprodutivos e de qualidade higiênicosanitária do leite (Milani \& Souza, 2010). O ambiente promove melhoria dos cascos e pernas, limpeza, baixa manutenção, diminuição da contagem de células somáticas, aumento da detecção de cio, além de proporcionar uma simplicidade no procedimento de manutenção e manipulação do esterco (Milani \& Souza, 2010). A estrutura deve conter ventilação natural do local, associado a uma saída de ar pelo telhado. As telhas de barro são as que permitem maior conforto térmico aos animais, seguidas das de alumínio, térmicas, cimento-amianto simples, zinco e fibra de vidro, além de que as telhas de vidro quando colocadas, são mais propicias a radiação solar, conduzindo um ambiente desconfortável termicamente (Milani \& Souza, $\underline{2010}$ ). Quando empregado um ambiente adequado ao animal, automaticamente a produção sofrerá mudanças significativas, pois o conceito de bemestar animal está diretamente associado às condições ambientais, como alojamento, alimento e conforto, além de envolver a área de descanso dos animais.

\section{Alimentação e nutrição}

Quando se pensa em alimentação de vacas leiteiras, deve-se ter em mente que esses animais precisam na composição de sua dieta, de água, concentrados, volumosos, suplementos, vitamínicos e minerais (NRC, 2001). A nutrição inadequada tem efeito direto na diminuição dos fatores que afetam o desemprenho reprodutivo de vacas de alta produção. A boa dieta deve suprir a necessidade de energia, conter níveis adequados de proteína e atingir as necessidades de vitaminas e minerais. Qualquer desequilíbrio destas, podem acarretar baixos índices de desempenho (Berchielli et al., 2011). Um dos desequilíbrios, são os números de células somáticas no leite, as células somáticas são estruturas de defesa do organismo que, quando há presença de patógenos nas glândulas mamárias, estes, migram para o interior das glândulas com o intuito de combatêlos. Portanto, a contagem de células somáticas (CCS) no leite, indica o estado sanitário do úbere. $\mathrm{Na}$ alimentação, utiliza-se a mineralização, que podem reduzir a contagem de células somáticas e contribuem para a melhoria da qualidade do leite (Berchielli et al., 2011).

\section{Formulação da dieta}

O primeiro passo para a formulação de uma dieta é o conhecimento da ingestão diária de alimentos e deve-se levar em consideração alguns aspectos importantes, como: peso vivo da vaca; produção de leite esperada; estágio de lactação; tempo de gestação (Pereira et al., 2010). Vacas em lactação exigem maior valor nutricional. No início da lactação, ocorre balanço energético negativo, em razão de obter maior necessidade para a produzir o colostro e o leite, e excede a quantidade de energia fornecida pela ingestão de matéria seca (Eustáquio Filho et al., 2010). A matéria seca (MS) é constituída pela porção restante do alimento, quando se elimina água. É onde estão todos os nutrientes (proteínas, minerais, carboidratos etc.) e está intimamente relacionada com a capacidade de consumo dos alimentos (Berchielli et al., 2011). Sendo assim, é o primeiro passo para formular dietas para vacas leiteiras, após ter o conhecimento do consumo de matéria seca pelo animal (Gonçalves et al., 2009). Vacas leiteiras em produção, necessitam de no mínimo $17 \%$ de fibra na matéria seca, para que o leite apresente teor de gordura normal. As fibras, são oriundas dos alimentos volumosos. Animais com média produção podem ser alimentados apenas com volumosos, enquanto que animais de alta produção, deve-se fazer um balanço de alimentos volumosos/concentrados (Berchielli et al., 2011).

\section{Seleção de alimentos}

Deve-se escolher alimentos variados, que estabelecerão a mistura final para os animais, buscando sempre alimentos volumosos (aquosos ou secos), concentrados energéticos, concentrados proteicos, suplementos minerais e vitamínicos. Deste modo, eleva-se as possibilidades de atingir 
as metas dos cálculos, por possuir alimentos com concentrações de nutrientes acima e abaixo das exigências nutricionais (Gonçalves et al., 2009). Para vacas leiteiras, a relação concentrado/ volumoso é maior para aquelas com maior produção de leite.

\section{Concentrado}

Concentrados, são alimentos que concentram em pequeno volume, uma grande riqueza em energia ou proteína, ou ambos. De maneira geral, eles possuem 55 a $95 \%$ de matéria seca. Os concentrados, possuem mais de $60 \%$ de nutrientes digestíveis totais (NDT) e baixos teores de fibra bruta (FB) (Berchielli et al., 2011). Os concentrados podem ser divididos em: concentrados energéticos e concentrados proteicos. Os concentrados energéticos possuem $16 \%$ ou menos de proteína bruta, o teor de fibra é variável, mas sempre menor que $18 \%$ e o teor de gordura depende do grão que será utilizado. Os concentrados proteicos: compreendem os farelos e farinhas de cereais (20 a $30 \%$ de PB). Os concentrados de origem vegetal são os mais usados na alimentação de bovinos (Berchielli et al., 2011).

\section{Volumosos}

Volumosos, são alimentos que apresentam alto teor de fibra bruta (FB), superiores a $18 \%$ e baixo valor energético. Constituem grande parte da ração, e apresentam baixa digestão de energia e proteína, entretanto, estes possuem papel fundamental no funcionamento do rúmen dos bovinos (Berchielli et al., 2011). Existem diferentes tipos de alimentos volumosos, sendo eles: forrageiras destinadas à pastagem; forrageiras verdes e picadas no cocho; silagens, que são forrageiras verdes armazenadas em silos, são conservadas por fermentação; fenos, que são armazenados por desidratação (Pereira et al., $\underline{2010)}$.

\section{Exigência nutricional de vacas leiteiras}

Exigência nutricional é a quantidade necessária de cada nutriente para a manutenção, crescimento, reprodução e produção. As exigências diárias em nutrientes e energia são estimadas com base no nível de produção e estado fisiológico. Segundo a categoria e nível de produção propostas pelo conselho americano de pesquisas (NRC, 2001). Importante ressaltar que as exigências em vacas primíparas, ou seja, primeira lactação é necessário aumentar $20 \%$ no valor, pois, estas ainda necessitam ganhar mais peso além de produzirem leite (Pereira et al., 2010).

\section{Forragens}

No regime de alimentação em pastagens, a produção de leite relaciona-se com a capacidade de suporte e o valor nutritivo do pasto. Capacidade de suporte da pastagem é relacionada aos fatores de clima, manejo, solo e adaptação da espécie da forrageira ao pastejo. Enquanto que, o valor nutritivo é avaliado pela sua digestibilidade, pelos teores de proteína bruta (PB) e de parede celular, intimamente relacionada com o consumo de matéria seca. Isso mostra que o animal irá produzir pela quantidade que ele comer e pelo paladar da forrageira oferecida (Oltramari \& Paulino, 2009, Reis \& Silva, 2011). Dentro das forrageiras, possuem aquelas que são as mais utilizadas, sendo elas: Brachiaria, Pennisetum e Panicum.

Gênero Brachiara: Normalmente, as braquiárias apresentam enraizamento nos nós, quando estão em contato com o solo. Sugere-se que apenas uma parte das pastagens seja constituída por forrageiras deste gênero, pois são mais susceptíveis a ataques de cigarrinha das pastagens (Deois flavopicta, Stal.). As espécies mais utilizadas em ordem decrescente, são: $B$. decumbens, $B$. brizantha, $B$. humidicola, $B$ ruziziensis, $B$. dictyoneura, $B$ mutica e B. arrecta. (Alvim et al., 2002).

Gênero Pennisetum: O Pennisetum purpureum, mais conhecido por capim-elefante, se destaca entre as forrageiras mais utilizadas nos sistemas de produção, em virtude do seu alto potencial produtivo e da sua qualidade. De acordo com Rêgo et al. (2010), o capim-elefante é capaz de mostrar elevado rendimento de forragem, quando convenientemente manejado e adubado.

A pastagem de capim elefante, quando bem manejadas podem suportar cargas animais muito elevadas. Porém, a produção de matéria seca (MS) deste gênero, apresenta-se estacional, concentrando grande parte da sua produção na primavera e no verão, sendo que no período seco, o crescimento e o valor nutritivo são reduzidos e a capacidade de suporte cai, necessitando adotar outras medidas de suplementação (Oltramari \& Paulino, 2009).

Gênero Panicum: Plantas deste gênero, são caracterizadas pelo seu grande potencial de produção de forragem, porém são menos flexíveis que as plantas do gênero braquiária, pois, 
apresentam limitações e/ou dificuldades para serem manejadas sob lotação contínua (Oltramari \& Paulino, 2009). Existe uma enorme possibilidade de sucesso na produção leiteira, desde que se use forrageiras de alta produtividade com manejo adequado. Portanto, deve-se propiciar às forrageiras um ambiente adequado para seu desenvolvimento, para que os esforços e ações empregadas resultem em produção animal eficiente e sustentável (Oltramari \& Paulino, 2009).

\section{Minerais}

Os minerais são elementos inorgânicos encontrados nos sais e em compostos orgânicos, como aminoácidos e proteínas. São considerados essenciais, ou seja, compreende em pelo menos uma função vital do animal. Podem ser considerados: macro minerais, que são elementos ganhos em poucos décimos de gramas e micro minerais, que são elementos ganhos em pequenas quantidades de microgramas por dia (Pedreira \& Berchielli, 2011). Eles são envolvidos em praticamente todas vias metabólicas do organismo, possuindo funções importantes na performance reprodutiva, no metabolismo energético, na manutenção do crescimento e outras funções fisiológicas, também no aumento da produtividade animal (Wilde, 2006). Todavia, , nem sempre os minerais são encontrados em quantidades desejáveis nos alimentos, necessitando de uma suplementação para compensar a deficiência nos alimentos (Peixoto et al., 2005, Tokarnia et al., 2000).

Os elementos minerais podem exercer quatro funções no organismo animal. Sendo elas, estrutural: estes, compõem estruturas nos órgãos e tecidos do corpo. Exemplo: Ca, P, Mg F e Si nos ossos e nos dentes; Fisiológica: ocorrem nos fluidos e tecidos como eletrólitos, estão relacionados com a manutenção da pressão osmótica, da permeabilidade de membranas, do balanço ácido - básico e irritabilidade dos tecidos. Exemplo: $\mathrm{K}, \mathrm{Na}, \mathrm{Cl}, \mathrm{Ca}$ e $\mathrm{Mg}$ no sangue; Catalítica: são catalisadores dos sistemas enzimáticos e hormonais, como componentes da estrutura de metalproteínas ou ativador do sistema; Reguladora: ação reguladora dos minerais na replicação e diferenciação celular. Exemplo: Ca influencia o sinal de transdução e $\mathrm{Zn}$ na transcrição (Pedreira \& Berchielli, 2011).

A mineralização em vacas leiteiras, tem como prioridade a melhora no desempenho reprodutivo, que consiste na diminuição do intervalo entre partos e aumento na taxa de concepção. Além de que, a mineralização aumenta a produção e melhora a qualidade do leite, reduzindo as células somáticas (Pedreira \& Berchielli, 2011).

\section{O cálcio relacionado com a atividade reprodutiva de vacas leiteiras}

Os mecanismos que dependem de Ca, estão relacionados com a síntese de esteroides nas glândulas adrenais e nos ovários, que podem influenciar na esteroidogênese, na liberação ou na utilização de colesterol e na conversão da progesterona. $\mathrm{O}$ início da lactação eleva a necessidade de $\mathrm{Ca}$. Uma vaca que produz $10 \mathrm{~kg}$ de colostro eliminará $23 \mathrm{~g}$ de $\mathrm{Ca}$ em uma única ordenha, representando nove vezes mais do que a quantidade de $\mathrm{Ca}$ circulante no organismo (Pedreira \& Berchielli, 2011).

É essencial a suplementação no período de transição (três semanas antes até três semanas depois do parto), pois com a suplementação, pode evitar transtornos no pós-partos, como por exemplo a retenção da placenta ou hipocalcemia. A hipocalcemia é relacionada com as desordens metabólicas como a mastite, prolapso uterino, cetose e metrite. A utilização de dietas aniônicas no pré-parto tem em vista à liberação de Ca ósseo, que evita a hipocalcemia (Pedreira \& Berchielli, 2011).

\section{Principais minerais relacionados com a reprodução de matrizes leiteiras}

O fósforo é um macro mineral essencial para a reprodução, é constituinte do ATP, que é responsável pelos processos metabólicos no organismo. Depois do fosforo, o segundo micro mineral mais importante, é o cobre que atua como cofator enzimático na síntese de hormônios, enzimas e vitaminas. O zinco, também atua como cofator enzimático, e se houver deficiência deste mineral compromete a concepção na fêmea. Selênio, participa da composição da enzima glutationa peroxidase que é relacionada com o combate aos radicais livres. Manganês é correlacionado com a intensidade de demonstração de cio em matrizes. Enquanto que o cobalto é precursor de vitamina B12, essencial para a flora microbiana. E por vez, o cromo é um micro mineral relacionado com o fator de tolerância à glicose, que determina a efetividade da insulina (Navarro-Alarcón et al., 2011). 


\section{Temperatura de armazenamento}

A temperatura e o período de armazenamento do leite até os laticínios/cooperativas determinam, de maneira seletiva e acentuada, a intensidade de desenvolvimento das várias espécies microbianas contaminantes e patogênicas. As temperaturas baixas impedem ou reduzem a multiplicação da maioria das bactérias e diminuem a atividade de algumas enzimas degradativas (Arcuri et al., 2006). Conforme a temperatura de crescimento, os microrganismos contaminantes são separados em três grupos principais: as mesófilas, que se multiplicam rapidamente na faixa de temperatura de $20^{\circ} \mathrm{C}$ a $40{ }^{\circ} \mathrm{C}$, as termófilas entre $44^{\circ} \mathrm{C}$ e $55^{\circ} \mathrm{C}$, e as psicrófilas entre $0^{\circ} \mathrm{C}$ e $15^{\circ} \mathrm{C}$. Além dessa categoria, existe as bactérias psicrotróficas que são capazes de se proliferar em temperatura muito baixas $\left(\leq 7^{\circ} \mathrm{C}\right)$, e as termodúricas, que resistem ao processo térmico de pasteurização. Essas classificações são de suma importância para compreendermos as causas e as adequadas correções para os problemas enfrentados referentes a qualidade do leite (Flores-Flores et al., 2015).

De acordo com Ministério da Agricultura, Pecuária e Abastecimento na Instrução Normativa $\mathrm{n}^{\circ}$ 62, de 29 de janeiro de 2011, a temperatura máxima de armazenamento do leite na propriedade rural é de 7 a $10^{\circ} \mathrm{C}$ no estabelecimento processador, com frequência de avaliação diária e mantendo-se o tempo de armazenagem do leite nas propriedades rurais por até 48 horas. No entanto, se o leite não for armazenado sob temperaturas inferiores a $4^{\circ} \mathrm{C}$, decorrerá um crescimento bacteriano, com níveis relacionados ao tempo de coleta do leite até o processamento nos laticínios/cooperativas. Há estudos que comprovam que o leite, quando armazenado sob temperatura de no máximo $7^{\circ} \mathrm{C}$, poderá conter o dobro da CBT, entre o terceiro e quarto dia após a coleta. Isto indica que a refrigeração do leite cru, até o estabelecimento processador, prevista na legislação de no máximo $7^{\circ} \mathrm{C}$, pode não ser suficiente para a manutenção da qualidade da matéria prima (Flores-Flores et al., 2015).

\section{Resfriamento e transporte}

$\mathrm{O}$ resfriamento do leite logo após a ordenha, e a coleta granelizada, são importantes medidas para garantir a qualidade microbiológica do leite. No entanto, a aplicação isolada dessas medidas, não é suficiente, faz-se necessário o uso de práticas higiênicas, durante toda a etapa produtiva para que a indústria possa receber o leite granelizado com uma baixa Contagem Bacteriana Total. (Lorenzetti., 2016).

Segundo BRASIL, (2002) a Contagem de Bacteriana Total do leite refrigerado deve estar abaixo de $750 \mathrm{mil} \mathrm{UFC} / \mathrm{mL}$ e a contagem de células somáticas (CCS) abaixo de 750 mil $\mathrm{CS} / \mathrm{mL}$, sendo que o leite deve ser mantido na propriedade rural em tanques de expansão com temperatura máxima de $7^{\circ} \mathrm{C}$ e após a chegada na indústria a temperatura deve ser de no máximo $10^{\circ} \mathrm{C}$.

O transporte do leite a granel, beneficia os produtores, com a redução dos custos com o frete, flexibilidade nos horários de ordenha e aumento de produtividade; as indústrias, com a redução dos custos com insumos e mão de obra para limpeza dos latões; e os consumidores, com a melhoria do produto (Ribeiro, 2000).

Conhecer as características do leite cru refrigerado após o recebimento pela indústria, são medidas importantes no monitoramento da qualidade dos derivados lácteos. $\mathrm{O}$ parque industrial brasileiro mostrar-se competitivo em termos de custos e qualidade, esse segmento do complexo agroindustrial também vem sofrendo uma competição cada vez maior, resultando dessa forma, em uma maior pressão no segmento produtivo por custos mais reduzidos e por uma qualidade melhor.

O transporte de leite a granel, por sua vez, temse mostrado aos países e às empresas que o adotaram como um grande avanço para a pecuária leiteira, pois tem permitido ganhos de qualidade, redução de trabalhos tidos como árduos (horários de ordenha, movimentação dos latões) e uma série de outras vantagens que fazem do sistema a granel superior ao tradicional sistema de coleta a latão.

A sazonalidade da produção tende a diminuir e os ganhos de qualidade são esperados, principalmente com a adoção de incentivos do tipo pagamento por qualidade do leite. A indústria pode receber o leite em um sistema mais organizado, uma vez que o tempo não é mais um fator limitante na coleta de leite. O sistema de transporte de leite a granel e todas as mudanças exigidas por ele, tem-se mostrado como uma alternativa considerável ao processo de tecnificação e melhoria do complexo agroindustrial leiteiro, além de apresentar-se com um grande potencial na redução dos custos de produção. 


\section{Considerações finais}

Os principais fatores que contribuem para a perda da qualidade do leite são: presença de doenças no rebanho (brucelose, tuberculose, mastite), falta de higiene durante a ordenha, limpeza e sanitização inadequadas dos equipamentos e utensílios de ordenha, má qualidade da água e acondicionamento e transporte em condições inapropriadas do ponto de vista de higiene e temperatura. Todos os esforços devem ser feitos para assegurar que o leite que sai da propriedade seja de alta qualidade. Diversos problemas de qualidade do leite estão sujeitos a ocorrer no dia-a-dia da produção ou do processamento.

Para cada problema há uma solução, e para resolvê-los, é necessária uma inspeção cuidadosa da produção primária e do processamento. Amostras de leite devem ser coletadas de maneira apropriada, refrigeradas e enviadas a um laboratório que possa analisá-las para determinar a origem ou causa do problema. Altas contagens bacterianas no leite cru podem aumentar muito rapidamente, mas podem ser reduzidas rapidamente a níveis aceitáveis se ações corretivas apropriadas forem tomadas. Por outro lado, alta contagem de células somáticas normalmente desenvolve-se num período de vários meses ou anos. Apesar de alguma melhora rápida poder ser alcançada pelo tratamento apropriado dos animais infectados, descarte de animais com mastite crônica e a adoção de um programa efetivo de controle da mastite, um considerável período de tempo pode ser exigido para que se alcancem níveis aceitáveis. Contudo é preciso permanente fiscalização e um trabalho de inesgotável conscientização e treinamento de todos os envolvidos na cadeia produtiva, além de contínuos incentivos à pesquisa visando a garantir o Brasil como país referência na produção e comercialização de produtos lácteos no mundo.

\section{Agradecimentos}

\section{FAPEMIG e CNPq}

\section{Referências bibliográficas}

Almeida, L. A. B., Brito, M. A. V. P., Brito, J. R. F., Pires, F. A. \& Benites, N. R. 2015. Tratamento de mastite clínica experimental por meio de ordenhas múltiplas em vacas leiteiras inoculadas com Staphylococcus aureus. Arquivo Instituto Biológico, 72, 1-6.
Alvim, M. J., Botrel, M. A. \& Xavier, D. F. 2002. As principais espécies de Brachiaria utilizadas no País. Embrapa Gado de Leite, Minas Gerais.

Arcuri, E. F., Brito, M. A. V. P., Brito, J. R. F., Pinto, S. M., Ângelo, F. F. \& Souza, G. N. 2006. Qualidade microbiológica do leite refrigerado nas fazendas Microbiological quality of refrigerated milk on farms. Arquivo Brasileiro de Medicina Veterinária e Zootecnia, 58, 440-446.

Baêta, F. C. \& Souza, F. C. 2010. Ambiência em edificações rurais: conforto animal. Universidade Federal de Viçosa, Viçosa.

Barbalho, T. C. F. \& Mota, R. A. 2005. Isolamento de agentes bacterianos envolvidos em mastite subclinica bovina no Estado de Pernambuco. Revista Brasileira de Saúde e Produção Animal, 2, 31-36.

Berchielli, T. T., Pires, A. V. \& Oliveira, S. G. 2011. Nutrição de Ruminantes. FUNEP, Jaboticabal, Brazil.

BRASIL. 2002. Ministério da Agricultura, Pecuária e Abastecimento. Departamento de Inspeção de Produtos de Origem Animal (DIPOA). Instrução Normativa n. 51, de 18 de set. de 2002. Aprova e Ofi cializa o Regulamento técnico de identidade e qualidade de leite cru refrigerado. Diário Ofi cial [da] República Federativa do Brasil, Brasília, DF, p. 13-22, 20 de set.

Cerqueira, M. M. O. P., Vargas, R. T., Cunha, A. F., Lage, A. D., Fonseca, L. M., Rodrigues, R., Oliveira Leite, M., Penna, C. F. A. M. \& Souza, M. R. 2009. Mastite em novilhas: importância e controle. Ciência Animal Brasileira, 1.

Costa, E., Melville, P., Ribeiro, A. \& Watanabe, E. 1999. Infecções intramamárias em novilhas primíparas no período pré ao pós-parto e sua importância no controle de mastite. Revista Napgama, 2, 16-20.

Costa, E. O., Carciofi, A. C., Benites, N. R., Melville, P. A., Pardo, R. B., Ribeiro, A. R. \& Watanabe, E. T. 1995. Estudo etiológico da mastite clínica bovina. Revista Brasileira de Medicina Veterinária, 17, 156-158.

Costa, H. N., Molina, L. R., Lage, C. F. A., Malacco, V. M. R., Facury Filho, E. J. \& Carvalho, A. Ú. 2017. Estimativa das perdas de produção leiteira em vacas mestiças Holandês x Zebu com mastite subclínica baseada em duas metodologias de análise. Arquivo 
Brasileiro de Medicina Veterinária $e$ Zootecnia, 69, 579-586.

Dawkins, M. S. 2017. Animal welfare and efficient farming: is conflict inevitable? Animal Production Science, 57, 201-208.

Duncan, J. \& Prasse, K. 1982. Patologia clínica veterinária. UFSM, Santa Maria.

Eustáquio Filho, A., Souza, F. M., Santos, P. E. F. \& Silva, M. W. R. 2010. Balanço energético negativo. Pubvet, 4, Art. 780-787.

Flores-Flores, M. E., Lizarraga, E., de Cerain, A. L. \& González-Peñas, E. 2015. Presence of mycotoxins in animal milk: A review. Food Control, 53, 163-176.

Gonçalves, L. C., Borges, I. \& Ferreira, P. D. S. 2009. Alimentação de gado de leite. EPMVZ, Belo Horizonte, Minas Gerais.

Grongnet, J. F., Santos, G. T., Piot, M. \& Toullec, R. 1996. Influence of some food additives on IgG plasma concentrations in newborn calves fed an immunoglobulin solution extracted from colostrum. Lait, 76, 303-309.

Kamiyama, C. M. \& Otenio, M. H. 2013. Aspectos sobre qualidade da água e qualidade de produtos na indústria de laticínios. Revista do Instituto de Laticínios Cândido Tostes, 68, 42-50.

Kehoe, S. I., Jayarao, B. M. \& Heinrichs, A. J. 2007. A survey of bovine colostrum composition and colostrum management practices on Pennsylvania dairy farms1. Journal of Dairy Science, 90, 4108-4116.

Lacerda, L. M., Mota, R. A. \& Sena, M. J. 2009. Qualidade microbiológica da água utilizada em fazendas leiteiras para limpeza das tetas de vacas e equipamentos leiteiros em três municípios do Estado do Maranhão. Arquivo do Instituto Biológico, São Paulo, 76, 569-575.

Lagger, J. R., Mata, H. T., Pechin, G. H., Larrea, A. T., Otrosky, R. N., Cesan, R. O., Caimier, A. G. \& Meglia, G. E. 2000. La importancia de la calidad del agua en producción lechera. Veterinaria Argentina, 27, 346-354.

Langoni, H., Guimarães, F. F., Costa, E. O. d., Joaquim, S. F. \& Menozzi, B. D. 2015. Milk cellularity and colony forming units in mastitis caused by coagulase-positive staphylococci and coagulase negative. Pesquisa Veterinária Brasileira, 35, 518-524.

Martins, R. P., Silva, J. A. G., Nakazato, L., Dutra, V. \& Almeida Filho, E. S. 2010. Prevalência e etiologia infecciosa da mastite bovina na microrregião de Cuiabá-MT. Ciência Animal Brasileira, 11, 181-187.

McDowell, R. E. \& Jones, R. G. 1974. Bases biológicas de la producción animal en zonas tropicales. Acribia, Zaragoza, Espanha.

Mendonça, C. L., Fioravant, M. C. S. \& Silva, J. A. B. A. 1999. Etiologia da mastite bovina. Veterinária Notícias, 5, 107-118.

Milani, A. P. \& Souza, F. A. 2010. Granjas leiteiras na região de Ribeirão Preto-SP. Engenharia Agrícola, 30, 742-752.

Müller, O., Bayer, M. J., Peters, C., Andersen, J. S., Mann, M. \& Mayer, A. 2002. The Vtc proteins in vacuole fusion: coupling NSF activity to V0 trans-complex formation. The EMBO Journal, 21, 259-269.

Navarro-Alarcón, M., Cabrera-Vique, C., RuizLópez, M. D., Olalla, M., Artacho, R., Giménez, R., Quintana, V. \& Bergillos, T. 2011. Levels of $\mathrm{Se}, \mathrm{Zn}, \mathrm{Mg}$ and $\mathrm{Ca}$ in commercial goat and cow milk fermented products: Relationship with their chemical composition and probiotic starter culture. Food Chemistry, 129, 1126-1131.

NRC. 2001. Nutrient Requirements of Dairy Cattle, 7th rev. edn. Natl. Acad. Press, Washington, DC., Washington.

Ocak, S. \& Önder, H. 2011. Placental traits and maternal intrinsic factors affected by parity and breed in goats. Animal Reproduction Science, $128,45-51$.

Oliveira, A. A., Melo, C. B. \& Azevedo, H. C. 2009. Diagnóstico e determinação microbiológica da mastite em rebanhos bovinos leiteiros nos tabuleiros costeiros de Sergipe. Ciência Animal Brasileira, 10, 226230.

Oltramari, C. E. \& Paulino, V. T. 2009. Forrageiras para gado leiteiro. Instituto de Zootecnia, Nova Odessa, São Paulo.

Pedreira, M. S. \& Berchielli, T. T. 2011. Minerais. In: Berchielli, T. T., Pires, A. V. \& Oliveira, S. G. (eds.) Nutrição de Ruminantes. FUNEP, Jaboticabal, Brazil.

Peixoto, P. V., Malafaia, P., Barbosa, J. D. \& Tokarnia, C. H. 2005. Princípios de suplementação mineral em ruminantes. Pesquisa Veterinaria Brasileira, 25, 195-200.

Pereira, E. S., Pimentel, P. G., Queiroz, A. C. \& Mizubuti, I. Y. 2010. Novilhas leiteiras. Graphiti Gráfica e Editora Ltda, Fortaleza, Ceará. 
Pereira, J. 2005. Fundamentos de bioclimatologia aplicados à produção animal. FEPMVZ, Belo Horizonte.

Perissinotto, M., Moura, D. J. \& Cruz, V. F. 2007. Avaliação da produção de leite em bovinos utilizando diferentes sistemas de climatização. Revista de Ciências Agrárias, 30, 135-142.

Prado, R. M., Paulin, M. F., Prado, I. N., Santos, G. T., Benchaar, C. \& Petiti, H., V. 2016. Milk yield, milk composition, and hepatic lipid metabolismo in transition dairy cows fed flaxseed or linola. Journal of Dairy Science, 99, 8831-8846.

Rêgo, M. M. T., Neiva, J. N. M., Cavalcante, M. A. B., Cândido, M. J. D., Clementino, R. H. \& Restle, J. 2010. Bromatological and fermentative characteristics of elephant grass silages with the addition of annato by-product. Revista Brasileira de Zootecnia, 39, 19051910.

Reis, R. A. \& Silva, S. C. 2011. Consumo de forragens. In: Berchielli, T. T., Pires, A. V. \& Oliveira, S. G. (eds.) Nutrição de Ruminantes. FUNEP, Jaboticabal, Brazil.

Ribeiro M.T. \& Teixeira S. R. L.2000. Qualidade do leite em tanques de expansão individuais ou comunitários. Glória Rural, 3, 28-35

Rodrigues, A. L., Souza, B. B. \& Pereira Filho, J. M. 2010. Influência do sombreamento e dos sistemas de resfriamento no conforto térmico de vacas leiteiras. Agropecuária Científica no Semiárido, 6, 14-22.

Romero, T., Beltrán, M. C., Rodríguez, M., De Olives, A. M. \& Molina, M. P. 2013. Short communication: Goat colostrum quality: Litter size and lactation number effects. Journal of Dairy Science, 96, 7526-7531.

Ruzante, J. M. \& Fonseca, F. L. F. 2001. Água: mais um fator para atingir a qualidade do leite. Revista Batavo, 8, 40-42.

Santos, G. T., Bertolini, D. A., Macedo, F. A. F., Prado, I. N. \& Martins, E. N. 1994. Variabilidade em imunoglobulina $\mathrm{G}$ ( $\mathrm{IgG}$ ) no colostro de cabra de primeira ordenha e absorção intestinal de $\operatorname{IgG}$ pelos cabritos recém-nascidos. Brazilian Archives of Biology and Technology, 37, 285-292.

Santos, G. T., Grongnet, J. F., Prado, I. N. \& Lareynie, J. 1988. Efeito da ordem de lactação sobre os níveis em imunoglobulinas $\mathrm{G}$ (IgG) do colostro bovino. Revista UNIMAR, 10, 31-38.
Santos, G. T., Macedo, F. A. F., Bertolini, D. A., Prado, I. N. \& Martins, E. N. 1995. Produção e níveis de IgG no colostro de cabra SRD e absorção intestinal de IgG pelos cabritos recém-nascidos. Brazilian Archives of Biology and Technology, 24, 989-997.

Schvarz, D. W. \& Santos, J. M. G. 2012. Mastite bovina em rebanhos leiteiros: Ocorrência e métodos de controle e prevenção. Revista em Agronegócio e Meio Ambiente, 5, 453-473.

Sgarbieri, V. C. 2004. Propriedades fisiológicasfuncionais das proteínas do soro de leite. Revista de Nutrição, 17, 397-409.

Silva, R. G. 2000. Introdução à bioclimatologia animal. Nobel, São Paulo.

Tizard, I. R. 2002. Imunologia Veterinária: introdução. Roca, São Paulo, Brasil.

Tokarnia, C. H., Döbereiner, J. \& Peixoto, P. V. 2000. Deficiências minerais em animais de fazenda, principalmente bovinos em regime de campo. Pesquisa Veterinária Brasileira, 20, 127-138.

Tozzetti, D. S., Bataier, M. B. N., Almeida, L. R. \& Piccinin, A. 2008. Prevenção, controle e tratamento das mastites bovinas-revisão de literatura. Revista Científica Eletrônica de Medicina Veterinária, 6, 1-7.

Werncke, D., Gabbi, A. M., Abreu, A. S., Felipus, N. C., Machado, N. L., Cardoso, L. L., Schmid, F. A., Alessio, D. R. M., Fischer, V. \& Neto, A. T. r. 2016. Qualidade do leite e perfil das propriedades leiteiras no sul de Santa Catarina: abordagem multivariada. Arquivo Brasileiro de Medicina Veterinária e Zootecnia, 68, 506516.

Wilde, D. 2006. Influence of macro and micro minerals in the peri-parturient period on fertility in dairy cattle. Animal Reproduction Science, 96, 240-249.

Willers, C. D., Ferraz, S. P., Carvalho, L. S. \& Rodrigues, L. B. 2014. Determination of indirect water consumption and suggestions for cleaner production initiatives for the milkproducing sector in a Brazilian middle-sized dairy farming. Journal of Cleaner Production, 72, 146-152.

Article History:

Received 28 February 2018

Accepted 26 March 2018

Available online 30 April 2018

License information: This is an open-access article distributed under the terms of the Creative Commons Attribution License 4.0, which permits unrestricted use, distribution, and reproduction in any medium, provided the original work is properly cited. 